\title{
A publicação como obsessão, a pressão como efeito e a integridade como discurso/desafio: uma análise crítico-provocativa da cientometria vigente
}

Murilo Mariono Vilaça!

\section{RESUMO}

Neste texto, em resposta ao gentil convite feito pelos editores, dedico-me a refletir sobre: (1) o valor conferido à publicação em periódicos acadêmico-científicos; (2) alguns problemas relativos à adoção de indicadores quantitativos utilizados na cientometria/ bibliometria atuais para avaliar a 'qualidade' da ciência; (3) alguns dos limites práticos do discurso normativo da integridade em pesquisa, especialmente em razão do contexto de pressão por publicação ("publicar ou perecer"). Para isso, recorro aos argumentos que venho sustentando ao longo dos últimos anos, reforçando e desenvolvendo alguns pontos que julgo centrais no presente debate.

Palavras-chave: Periódicos acadêmico-científicos. Cientometria/bibliometria. Pressão por publicação. Integridade em pesquisa

1 Doutor em Filosofia (UFRJ) e em Educação (UERJ), Pesquisador da Fiocruz, Docente do Programa de Pósgraduação em Bioética, Ética Aplicada e Saúde Coletiva. E-mail: murilo.vilaca@fiocruz.br 
Publication as an obsession, pressure as an effect and integrity as a discourse/challenge: a critical-provocative analysis of the scientometrics in effect

\begin{abstract}
In this text, in response to the kind invitation received from the editors, I dedicate myself to reflecting on: (1) the value placed on publications in academic-scientific journals; (2) some problems related to the adoption of quantitative indicators by the current scientometrics/bibliometrics to evaluate the 'quality' of science; (3) some of the practical limits of the normative discourse on research integrity, especially due to the pressure to publish context ("publish or perish"). For that, I resort to the arguments that I have been supporting over the last years, reinforcing and developing some points that I consider central to the present debate.
\end{abstract}

Keywords: Academic-scientific journals. Scientometrics/bibliometrics. Pressure to publish. Research integrity

La publicación como obsesión, la presión como efecto y la integridad como discurso/ desafío: un análisis crítico provocativo de la cientometria vigente

\title{
RESUMEN
}

En este texto, en respuesta a la gentil invitación realizada por los editores, dedícome a reflexionar sobre: (1) el valor atribuido a la publicación en periódicos académicocientíficos; (2) algunos problemas relativos a la adopción de indicadores cuantitativos utilizados en la cientometria/bibliometria actuales para evaluar la "calidad" de la ciencia; (3) algunos de los límites prácticos del discurso normativo de la integridad en investigación, especialmente en la razón del contexto de presión por publicaciones ("publicar o perecer"). Para esto, recorro a los argumentos que vengo sosteniendo a lo largo de los últimos años, reforzando y desarrollando algunos puntos que juzgo centrales en el presente debate.

Palabras clave: Periódicos académico-científicos. Cientometria/bibliometria. Presión por publicar. Integridad en investigación 
Primeiramente, agradeço aos editores pelo gentil convite para (tentar) contribuir para a reflexão sobre os periódicos científicos. É um prazer e honra, bem como uma responsabilidade.

Meus modestos objetivos neste artigo são: destacar alguns aspectos do papel/valor atribuído aos periódicos na cientometria atual, tangenciar alguns dos problemas relativos a isso e problematizar a ideia de integridade em pesquisa (ética em publicação).

Vou direto aos pontos (que desenvolverei abaixo):

(1) Publicar um artigo em um periódico científico virou, para alguns, uma obsessão;

(2) Os periódicos acadêmico-científicos não dizem nada sobre a qualidade do conhecimento nele publicado, possuem altíssimo valor no mercado acadêmico-científico e expõem que não sabemos (quase) nada sobre o que é qualidade acadêmico-científica (epistemológica);

(3) A integridade em pesquisa é um belo discurso pela ética acadêmico-científica, mas é prática?

\section{A ORDEM É PUBLICAR!...}

Publicar artigos em periódicos acadêmico-científicos - por causa do valor que atribuímos a ela - é uma espécie de passaporte para a entrada em um seleto grupo de acadêmicos-cientistas bem-sucedidos ou relevantes.

Alguns discursos provenientes da pesquisa de De Meis et al. (2003, p. 1139) apontam para essa tendência no meio acadêmico-científico atual:

A submissão de um artigo evoca emoções fortes e, freqüentemente, o entrevistado preocupa-se com o que seus colegas pensarão dele quando souberem do aceite ou reprovação:

10. "Minha maior preocupação era publicar, ser reconhecido ... era um tipo de autoafirmação, então eu poderia dizer a eles: 'Olhe, eu sou bom!'”;

11. "Quando a revista não aceita, você se sente como se não fosse apenas o seu artigo, mas você mesmo que é rejeitado ... Eles olham para você como se você não merecesse estar lá ... é muito mau pressentimento!";

12. "É um grande sentimento ter um artigo aceito, principalmente quando você sabe que muitas pessoas rejeitam seus artigos ...".

Os periódicos científicos não têm a mera função de veículos de disseminação/divulgação (publicização) de um conhecimento produzido pelos acadêmicos e cientistas, o que é fundamental, diga-se de passagem. Além disso - e, talvez, mais relevantemente - os periódicos legitimam o conhecimento e exercem uma grande influência sobre a regulação da ciência, a avaliação do seu desenvolvimento, bem como sobre a distribuição/aquisição de recursos/investimento e as oportunidades/empecilhos de carreira/emprego.

Camargo Júnior (2010), destacando que são um campo de disputa e poder (campo não neutro), os periódicos especializados têm um papel importantíssimo na produção da ideia de "evidência científica". Em conformidade com o que afirmei, os periódicos não são 
lugares em que verdades científicas são meramente publicadas, mas também produzidas, e há um intrincado jogo político envolvido, o qual se distancia e, por vezes, antagoniza-se com as questões, por assim dizer, propriamente epistêmicas.

Utilizando um jogo de palavras, para alguns (que não parecem ser poucos), publicar (gravar o nome no Olimpo dos produtivos) é o ponto-chave, em vez de publicizar (compartilhar um conhecimento, defender um ponto de vista fundamentado, expor uma ideia à crítica, prestar contas à sociedade, etc.) (VILAÇA; PALMA, 2013). Não estou, de modo algum, julgando e condenando esses 'alguns'. Para mim, o contexto em que vivemos propicia fortemente a primeira opção. Talvez, ela seja, inclusive, a mais prudente, uma espécie de conservatio vitae, um estratégia de sobrevivência na 'selva' acadêmico-científica (VILAÇA; PALMA, 2016). Desenvolverei isso mais à frente.

Publicar cria o que denominei de capital curricular (VILAÇA; PALMA, 2013), uma vez que, como argumentei longamente em outros trabalhos, aos artigos está sendo atribuída a função de moeda no meio acadêmico-científico, seguindo uma lógica análoga à de mercado, em um contexto que vem sendo definido como de pressão por publicação ou de publicar ou perecer (VILAÇA, 2013). Vejamos o que os dados de De Meis et al. (2003, p. 1138-9) apontam sobre isso:

A publicação de artigos e o impacto dos periódicos onde os artigos são publicados eram a principal preocupação tanto dos estudantes de pós-graduação quanto dos pesquisadores. Narrativas típicas foram:

4. "Ele é um sujeito muito útil ... ele tem ótimas ideias e eu sempre aprendo muito com ele, mas isso não é suficiente ... Neste lugar, você só é reconhecido quando tem publicações ... o resto não importa";

5. "Ele [o orientador da Tese] não se preocupa com a minha tese. Ele acredita que uma tese é a consequência do bom trabalho e bom trabalho significa artigos publicados em bons periódicos";

6. "Você sente uma pressão constante para publicar ...";

7. "O que ouvimos é que você vale o que você publica ... a moeda nesta arena são as publicações";

8. "Meu chefe tem muitas publicações ... mas quando você vai e procura pelo que ele descobriu ... você pode defini-lo em três frases: ele descobriu isso, isso e aquilo. O resto foi treinar estudantes e obter financiamento".

Segundo expressão que utilizei noutro artigo, há uma espécie de periodicocracia quantativista do conhecimento (VILAÇA; PALMA, 2013). Ou seja, um dos fatores mais importantes no processo de avaliação da ciência são os artigos publicados em periódicos ou, mais precisamente, os periódicos onde os artigos são publicados. E quantidades (de artigos, de citações, de indicadores bibliométricos) são fundamentais. Publicar (com base em números) virou norma, constrangendo, induzindo e normalizando comportamentos, moldando indivíduos e, com isso, instituições que eles compõem.

O poder/valor acadêmico-científico (supostamente qualificador) atribuído aos artigos/periódicos é tão grande, que a 'qualidade' de Teses e Dissertações está, por vezes, diretamente atrelada a eles. Na avaliação CAPES da pós-graduação, um dos quesitos 
avaliados (o terceiro) é denominado Corpo Discente, Teses e Dissertações. Parte considerável desse quesito (o item 3.3) (em regra, 40\%) diz respeito à "Qualidade das Teses e Dissertações [...]". A mensuração da 'qualidade' depende, em algumas áreas (por exemplo, Ciências Biológicas III, Educação Física, Engenharia IV, Medicina II, etc.), do fato de a Tese/Dissertação ter sido publicada em forma de artigo, avaliação que é feita de acordo com o Qualis periódicos. Há programas de pós-graduação que, inclusive, já dão a opção (e a estimulam) de que os mestrandos e doutorandos não defendam Teses/Dissertações, mas artigos. Há, por outro lado, aqueles que cobram que os candidatos apresentem, na seleção para o mestrado/doutorado, suas publicações mais importantes, induzindo a uma iniciação produtivista precoce.

Na lógica citada (relativa ao quesito), é como se as bancas de defesa de Teses e Dissertações não fizessem muito sentido. Afinal, se uma Tese ou Dissertação for aprovada pela banca de avaliação, mas não for publicada em forma de artigo, especialmente em um periódico 'dos bons', ela deixa de ser considerada uma publicação qualificada? Provocativamente questionando, o título de Doutor/Mestre deveria ser revisto, caso o recém-mestre ou recém-doutor não consigam 'emplacar' um artigo? Esse poder/valor, na minha visão, excessivos dados aos periódicos confirmam a ideia de que estamos diante de uma periodicocracia, no mínimo, questionável, de uma cientometria equivocada, distorcida e deturpadora.

\section{... E TEM QUE SER EM 'BONS' PERIÓDICOS: SOBRE NOSSAS FICÇÕES ‘QUALITATIVAS’}

Como tenho argumentado ao lado de outros autores (e vimos no discurso 5 supracitado), não é propriamente o conteúdo do artigo que confere a ele um alto ou baixo valor acadêmico-científico, tampouco nos modelos de avaliação. Em vez disso, indicadores cientométricos/bibliométricos - como o Fator de Impacto $^{2}$ - são, via de regra, utilizados para determinar o valor ou 'peso' de um artigo.

Uma das mais detalhadas revisões de literatura sobre cientometria ou cienciometria foi escrita por Mingers e Leydesdorf (2015). Segundo Nalimov (1971 apud MINGERS; LEYDESDORFF, 2015, p. 1) definida como "os métodos quantitativos de pesquisa sobre o desenvolvimento da ciência como um processo informacional". Segundo Pritchard (1969 apud MINGERS; LEYDESDORFF, 2015, p. 1), bliliometria é "a aplicação de métodos matemáticos e estatísticos aos livros e outros meios de comunicação". Segundo Nacke (1979 apud MINGERS; LEYDESDORFF, 2015, p. 2), infometria é "o estudo da aplicação de métodos matemáticos aos objetos de informação da ciência". De acordo Björneborn

2 É um produto da Thomson Reuters / Institute for Scientific Information, que edita o Journal Citation Reports ${ }^{\circledR}$, calculando o Fator de Impacto (JCR) dos periódicos. Esse indicador cientométrico é calculado assim: se X é o número de vezes que os itens citáveis (usualmente, artigos, ensaios, notas, resenhas) publicados por um periódico indexado pela empresa foram citados em dado período (2016-2017) em outros periódicos também indexados por ela; e se $\mathrm{Y}$ é o número total destes itens publicados no mesmo período; o FI do periódico no ano subsequente (2018) é igual a X/Y. 
\& Ingwersen, Thelwall \& Vaughan e Thelwall et al. (2004, 2004, 2005 apud MINGERS; LEYDESDORFF, 2015, p. 2), Webmetria é "o estudo dos aspectos quantitativos da construção e uso de recursos de informação, estruturas e tecnologias na Web, com base em abordagens bibliométricas e informétricas". Altmetria, segundo Priem (apud MINGERS; LEYDESDORFF, 2015, p. 2), é "o estudo e uso de medidas de impacto acadêmico baseadas em atividades em ferramentas e ambientes online".

Silva e Bianchi (2001, p. 6) fornecem definições que destacam a dimensão quantitativa da avaliação:

[...] bibliometria ou cientometria que é definida como o estudo da mensuração do progresso científico e tecnológico e que consiste na avaliação quantitativa e na análise das inter-comparações da atividade, produtividade e progresso científico. Em outras palavras, a cientometria consiste em aplicar técnicas numéricas analíticas para estudar a ciência da ciência. Já a bibliometria consiste no tratamento e na análise estatística da mensuração destes resultados e desenvolvimentos através das diferentes publicações científicas refletidas em artigos, livros e em revistas científicas editadas.

Poderia me estender quase indefinidamente aqui sobre o assunto, mas penso que uma coisa está evidente: os estudos cientométricos/bibliométricos são estratégias de quantificação da ciência, e não de avaliação qualitativa.

Uma das críticas mais frequentes (e claramente procedentes) ao modelo CAPES de avaliação da pós-graduação é justamente de que ela quantifica produtos (resultados), e não avalia o processo. A lógica, por assim dizer, contábil desse modelo não parece ser capaz de extrair elementos clara e inquestionavelmente qualitativos daquilo que visa a avaliar, a saber, o desenvolvimento da Academia e ciência nacionais.

Têm sido comuns matérias sobre os números da ciência nacional, quer com tons de lamento, quer de celebração. Os pesquisadores brasileiros têm publicado mais artigos em periódicos, celebra-se (sobretudo se forem publicados em periódicos internacionais ${ }^{3}$ e com alto Fator de Impacto-valor de mercado); publicado menos artigos, lamenta-se. Os artigos têm sido mais citados, celebra-se; os artigos não têm sido citados, lamenta-se. E daí por diante.

Percebam que estamos falando de mais (ou menos), e não de melhores (ou piores). Isto é, estamos falando de quantidade, e não de qualidade. Na esteira do questionamento de Rodrigues (2007), mais (e internacionalmente) é (necessariamente) melhor? Se a resposta fosse positiva, seria imperioso admitir que todo artigo publicado internacionalmente e muito citado possuiria boa qualidade (bem como que, sentido contrário, uma pesquisa não publicada internacionalmente e com pouca quantidade de citações tenderia a ser ruim), o que forçaria uma conclusão: não sabemos nada, a priori, sobre a qualidade de uma pesquisa

3 A chamada internacionalização da ciência brasileira é uma das obsessões de quem gerencia a política científica nacional, mais uma espécie de biombo forjado para encobrir nossa falta de critérios qualitativos. 
transformada em artigo. Nossa avaliação só poderia ser a posteriori e estaria baseada forte ou exclusivamente na quantidade. Já falei sobre a lógica quantitativa do Fator de Impacto, que é apenas um dos indicadores cientométricos (portanto, quantitativos) utilizados atualmente, e tangenciei a sedução que ele exerce sobre muitos pesquisadores, pode ser considerado como um 'canto pseudo-qualitativo da sereia cientométrica/bibliométrica'. Mais há várias versões desse canto (por exemplo, o Índice-H relativo a pesquisadores e a periódicos; Eigenfactor ${ }^{\mathrm{TM}}$ Metrics; SCImago Journal Rank (SJR) indicator, etc.).

Segundo Silva e Bianchi (2001, p. 7):

Dois são os conjuntos de indicadores bibliométricos: 1) Os indicadores quantitativos da atividade científica refletida no número de publicações e 2) Os indicadores de impacto, baseados no número de citações obtidas pelos trabalhos publicados e que caracterizam a importância desta produção científica, em função do reconhecimento outorgado por outros pesquisadores.

Silva e Bianchi (2001, p. 7-8) destacam, sobre os indicadores de impacto, que

O número de publicações é um indicador meramente quantitativo, que não leva em conta a qualidade ou a importância do conteúdo do trabalho realizado. É claro que nem todas as publicações despertam o mesmo interesse e nem contribuem de maneira semelhante para o progresso científico da área.

Não obstante tal afirmação, os autores apostam na possibilidade de que a quantificação possa revelar alguma qualidade, afirmando que "para valorizar de alguma forma a qualidade dos trabalhos publicados foram introduzidos dois outros indicadores: o número de citações que um artigo recebe na literatura e o fator de impacto da revista ou periódico em que a publicação é feita" (SILVA; BIANCHI, 2001, p. 8). Citam, nesse sentido, o impacto dos trabalhos (número de citações recebidas por um artigo) e impacto das revistas (número médio de citações que os trabalhos publicados recebem). Mas, em consonância com o que tenho sustentado aqui, eles admitem:

Seria importante, contudo, destacar que impacto e qualidade de um trabalho científico não são sinônimos. A qualidade se refere ao conteúdo científico da publicação, à adequação da metodologia, à clareza da redação e à originalidade do delineamento e das conclusões. [...] o número de citações de um artigo científico depende obviamente de sua qualidade, mas também de outras variáveis como o prestígio do autor(es), de sua instituição de trabalho, a atualidade do tema investigado, a língua utilizada e o que oferece, em termos de difusão, a revista ou periódico em que foi publicado. Em resumo, o número de citações dadas a um trabalho científico deve ser considerado como um indicador parcial de sua qualidade." (SILVA; BIANCHI, 2001, p. 8).

Apesar de serem fortemente questionáveis, no Brasil, por exemplo, há um sistema - Qualis Periódicos - que utiliza amplamente indicadores bibliométricos (destacadamente 
o Fator de Impacto) para atribuir pontos (peso ou valor) aos artigos numa correlação com a Qualisdade dos periódicos, os quais são estratificados/hierarquizados4.

Recorro novamente a De Meis et al. (2003, p. 1139):

Quando os entrevistados se referiam ao trabalho de seus colegas, geralmente se referiam ao número de publicações e aos periódicos, não sabendo claramente o que havia sido descoberto. A reputação científica parece, portanto, ser construída com base na cienciometria, assumindo que o impacto dos periódicos reflete a novidade e a importância das descobertas:

9. "Eles avaliam as pessoas pelo número de publicações ... e então as classificam pelo impacto dos periódicos: cientistas de alto impacto e baixo impacto ...".

Segundo Ruiz, Greco e Braile (2009), periódicos costumam celebrar o aumento dos seus Fatores de Impacto, bem como a entrada no seleto grupo de periódicos editorados por editoras renomadas ou em bases indexadoras prestigiadas. Não raro, quando isso ocorre, seu valor no mercado acadêmico aumenta, numa evidente lógica concorrencial (entre os 'bons' e 'maus' periódicos). Como exemplo, cito:

No editorial de fevereiro de 2008 da CLINICS, o editor científico informava, em alusão à citação de capa, que a revista - no seu quarto ano de existência - estava incluída e indexada no Journal Citation Reports (JCR) do Institute for Scientific Information (ISI) [1]. Ressaltava o editor que a inclusão da revista na base de dados do ISI era a última indexação que faltava à CLINICS, e assim o Fator de Impacto (FI) da revista passaria a ser medido a partir de 2009. Informava também que o FI extra-oficial da revista era de 0,8, enfatizando que tal resultado colocaria a CLINICS em boa posição frente às 23 revistas brasileiras da época indexadas naquela base de dados. Citava também o fato da existência de poucas revistas científicas nacionais com valor superior a 1,0. (RUIZ; GRECO; BRAILE, 2009, p. 274).

A título de observação, cumpre dizer que a Clinics, que foi apontada como um exemplo de sucesso e o seu editor como um exemplo de comportamento ético, teve, em 2013, seu Fator de Impacto suspenso pela prática de stacking (empilhamento de citações). Aliás, a própria forma como o periódico atingiu seu prestígio acadêmico-científico é, no mínimo, questionável. Maurício da Rocha e Silva - o editor bem-sucedido - explicou suas táticas, seus 'truques' ou "pulos de gato" nem sempre éticos, como ele mesmo denomina (MARCOLIN; ZORZETTO, 2012, s/p., grifo meu, trecho entre colchetes incluído):

Entramos (a Clinics) no ISI em 2007. Leva três anos para aparecer o primeiro impacto. Em 2009 batemos em 1,59 e ficamos atrás apenas de Memórias. Em 2010 caímos um pouquinho, para 1,42, e estamos em terceiro. Os resultados de 2011 ainda não saíram, mas pelos meus cálculos voltaremos para o segundo lugar. A revista de

4 Os critérios para estratificação/hierarquização dos periódicos, bem como os pontos atribuídos a cada estrato (A1, A2, B1, B2, B3, B4, B5 e C) variam tanto diacronica quanto sincronicamente. Para detalhes do que foi adotado pelas áreas no último ciclo de avaliação quadrienal, ver Documentos de Área (disponível em http://avaliacaoquadrienal.capes.gov.br/documentos-de-area). 
Manguinhos é meu modelo. Eles deram o primeiro salto acima de 2 publicando um suplemento sobre a doença de Chagas. Todo mundo cita. Então eu criei um suplemento sobre neurocomportamento, com artigos de revisão do Miguel Nicolelis e do inglês Timothy Bliss. O Bliss foi quem descobriu nos anos 1980 como os neurônios fixam a memória. Ele tem um artigo com mais de 5 mil citações [...].

Nos anos 1990 fui do conselho editorial de uma revista americana, a Circulatory Shock. Como ela estava mal financeiramente, seus donos decidiram matar a revista e criar uma nova, chamada Shock. Fui um dos fundadores como membro editorial. Para dirigir veio um cientista muito bom em editoração. Aí fizemos um pacto de sangue. Combinamos que as 30 pessoas do corpo editorial teriam de mandar um artigo por ano para a Shock. E esse artigo teria de ser citado de três a quatro vezes nos dois anos seguintes em outras revistas do Primeiro Mundo. Todos fizeram. No primeiro ano, o impacto foi de 0,7 . Tem de se considerar que uma revista americana entra no ISI [Institute for Scientific Information, serviço de bases bibliométricas que hoje faz parte da Thomson Reuters, responsável pelo cálculo do fator de impacto das publicações] no dia seguinte ao em que é criada e isso ajuda muito no impacto. Em 15 anos ela chegou a 3,5. Eu aprendi esses pulos de gato. Há alguns éticos e outros nem tanto. O editor da Shock é um modelo de comportamento ético.

Ao lado de outros autores, já listei alguns dos vários problemas do Fator de Impacto (VILAÇA; PALMA, 2013). Vejamos o que Ruiz, Greco e Braile (2009, p. 276) dizem:

O Fl e a sua forma de contagem e de determinação, segundo vários autores, é mal construído e mal utilizado como medida de qualidade científica. Abaixo citamos alguns pontos comumente aventados para justificar a assertiva acima, que consideram o índice como inapropriado:

- A qualidade do material publicado não pode ser aferida através do tempo. A quantificação das citações, pelo período de dois anos, é arbitrária e foi determinada pelo ISI. Os artigos que compõem o denominador do cálculo do FI também são determinados pelo ISI e a regra de escolha destes artigos também não é clara e é duvidosa.

- O número dos periódicos incluídos na base de dados é mínimo em relação ao que, na realidade, é devidamente publicado.

- Os artigos de revisão são geralmente os mais citados quando comparados com os artigos originais, sendo que este dado favorece os periódicos que optam pela publicação deste tipo de contribuição como parte de estratégia editorial.

- O FI não discrimina as citações dos próprios autores de seus artigos, sendo que estes representam, na realidade, cerca de 1/3 de todas as citações que são contabilizadas.

- O número de erros nas listas de referências é habitual e isto ocorre em aproximadamente $1 / 4$ de todas as referências citadas nos artigos, o que prejudica inevitavelmente a acurácia do Fl.

- Assumir uma conectividade positiva entre as citações e o artigo produzido é equivocado, e muitas vezes o artigo cita artigos suspeitos ou de qualidade duvidosa. A citação não é considerada garantia de qualidade nem do artigo nem do citado.

Adicionalmente, cabe destacar que o Fator de Impacto simplesmente não traduz a tradição de certas áreas, como as que compõem as Ciências Humanas e Sociais. Nelas, a publicação de livros e capítulo de livros é muito mais relevante do que em outras áreas, 'produtos' acadêmico-científicos que não são considerados pelo Fator de Impacto. 
Sem o peso empírico do estudo de De Meis et al. (2003), mas considerando a repercussão do texto como um indicativo de que, às vezes, a fronteira entre ficção e realidade fica bastante nebulosa, recorro a um diálogo ficcional construído por Vilaça e Pederneira (2013, p. 237-8), a fim de expressar quão tosca pode ser nossa relação com esse indicador de 'qualidade':

\section{Quinto ato: $O$ docente de impacto}

-"E aí, tem publicado?", inicia-se um capcioso diálogo entre pesquisadores de um programa de pós-graduação nota 7.

-"Minha produção está em dia, indo muito bem", orgulha-se um deles.

-"Que bom. Isso é bom tanto para você quanto para o programa", comenta o outro. -"É ... aquele artigo que enviei para aquela revista de altíssimo fator de impacto foi aceito", comemora o professor.

-"Qual é mesmo o fator de impacto dela?".

-"23,459!", responde orgulhoso.

-"Meus parabéns", congratula-o. "Mas me tire uma dúvida: como esse fator ${ }^{7}$ é precisamente definido?», pergunta.

-»hahaha ... não sei bem, mas o que importa é que a revista tem um alto fator de impacto ... e isso rende muitos pontos no currículo", confessa inescrupulosamente. -"Acho que envolve número de citações e de artigos, algo assim", tentando ajudar o colega. "Aliás", completa, "acho isso bem relativo".

-"Como assim?", surpreende-se o orgulhoso autor, pensando na possibilidade de inveja do colega.

-"Não estou desmerecendo a sua 'conquista'", defende-se, "só acho que número de citações não garante a qualidade da revista, menos ainda dos textos nela publicados. Pense comigo, se alguém famoso publica um artigo, provavelmente ele será muito lido e muito citado. Mas um autor pode citar aquele artigo motivado por vários interesses, como 'agregar o valor' da revista e daquele autor famoso ao seu texto, mesmo que seja incapaz de avaliar o que foi pesquisado e publicado. Além disso, como se faz nos casos em que artigos publicados em grandes revistas são denunciados e cancelados por fraude? As citações recebidas são canceladas? O fator de impacto é revisto? Enfim...".

-"É, você pode ter alguma razão", comenta o não persuadido ‘autor de impacto».

Outro aspecto que gostaria de destacar rapidamente, que confirma o alto valor dos artigos/periódicos, é o fato de terem tornado-se uma 'mina d'ouro'. Segundo Monbiot (2011), em 2010, o lucro operacional da maior editora científica do mundo - a Elsevier - foi de $36 \%$ sobre cobranças de $£ 2,000,000,000$. Ainda segundo o autor, cujos dados precisam ser atualizados, a Elsevier cobrava US\$31,50, a Springer € 34,95, e a Wiley-Blackwell US\$ 42 por um acesso de 24h a um artigo publicado em um dos seus periódicos. No Brasil, há periódicos que cobram pela publicação de artigos. ${ }^{5}$ Há alguns que cobram

5 Por exemplo, Brazilian Journal of Medical and Biological Research (Medicina B2 e Ciências Biológicas II A2): R\$ 3.300,00 (para autores brasileiros) e US\$ 1.600,00 (para autores estrangeiros); Revista de Saúde Pública (A2 - Saúde Coletiva): R\$2.200,00 (artigos originais, de revisão e comentário); Acta Ortopédica Brasileira (B1 - Medicina II): R\$ 1.500,00 (US\$ 600); Arquivos do Instituto Biológico (B1 - Ciências Agrárias): R\$ 60,00. 
pela submissão, e pela publicação. ${ }^{6}$ O Fator de Impacto/Qualis (valor de mercado do periódico) são pontos fundamentais nesse quadro de mercantilização do conhecimento acadêmico-científico, que segue uma clara lógica de mercado (valor de mercado, oferta-demanda, etc.), como desenvolvi detalhadamente em outro momento (VILAÇA, 2013). É o preço da 'qualidade', da visibilidade, da ascensão ao seleto grupo dos pesquisadores de alto impacto ('bem-sucedidos').

Em suma: o periódico, em si, não diz nada sobre a qualidade do conhecimento publicado nele. Senão, artigos publicados em periódicos renomadíssimos (com alto Fator de Impacto) nunca poderiam ser de baixa qualidade (como ocorre), tampouco ser retratados/ despublicados (idem). Por outro lado, a existência de periódicos sem Fator de Impacto e/ ou do estrato B5 ou C (segundo o Qualis) seriam um acinte à ciência e Academia, dada sua natureza de 'selo má qualidade'. Dito de outro modo, o periódico não é, nem deve ser tratado como um 'selo boa qualidade', como uma chancela inquestionável. Na verdade, faltam-nos critérios epistemológicos claros e, por vezes, minimamente consensuais para definir o que é qualidade de uma pesquisa. A chamada revisão por pares em regime duplo-cego não preenche essa constrangedora lacuna no processo de avaliação da ciência e da Academia. Conforme aponta Botomé (2011), o processo de avaliação é, muitas das vezes, de julgamento, e de julgamento arbitrário (do tipo gosto ou não do referencial adotado, concordo ou não com a visão do autor, "não me citou, logo eu que sou uma referência em tal tema", etc.), sem qualquer senso de justiça e/ou qualidade acadêmico-científico, dando margem, por um lado, ao seu uso como meio de linchamento intelectual, como afirma o autor, de revanche ou perseguição; e, por outro lado, de favorecimento, troca de favores, jogo de interesses (como vimos no caso da Clinics). Assim, como resultado do julgamento sem critérios claros, a condenação sumária (reprovação do artigo, inclusive sem justificativas claras) e a absolvição (aprovação para publicação igualmente sumária, sem parecer ou em tempo recorde) podem ser uma questão de sorte ou azar.

Para ilustrar, chamou-me a atenção o caso de um artigo 'avaliado' e aprovado em apenas um dia, possivelmente em menos de vinte e quatro horas, enquanto a média de tempo de avaliação entre todos os outros publicados no mesmo número foi imensamente discrepante $^{7}$ (VILAÇA, 2013). A título de observação, o autor principal do artigo, é um renomado cientista, bolsista de produtividade em pesquisa do CNPq - Nível 1A. Embora não seja possível afirmar categoricamente, esse caso pode ilustrar alguns dos problemas presentes no processo de avaliação/julgamento: a autoria pode encurtar o prazo e, até mesmo, determinar a aprovação de um artigo; a cegueira da avaliação pode não ser tão

6 Por exemplo, Acta Paulista de Enfermagem (A2 - Enfermagem): R\$ 350,00 (taxa de submissão) e R\$ 1.600,00 (taxa de edição); Arquivo Brasileiro de Medicina Veterinária e Zootecnia (A2 - Medicina Veterinária): R\$ 60,00 (taxa de submissão) e R\$150,00 (taxa de publicação/por página - os artigos podem ter até 15 páginas, ou seja, podem custar até $\mathrm{R} \$ 2.250,00$ )

7 De acordo com informação presente no artigo, o texto foi recebido em 4 de agosto de 2003 e foi aceito em 5 de agosto de 2003. Rara celeridade avaliativa à parte, a média aritmética de tempo de avaliação dos outros dezenove artigos publicados no mesmo número - com tamanhos, por sinal, compatíveis ao daquele - foi de 7,89 meses. 
cega assim (há formas de reconhecer a autoria, o que não necessariamente interrompe o processo que deveria ser anônimo); editores podem aprovar (sem passar pela estimada revisão por pares) artigos ou induzir a aprovação (selecionando revisores), porque o texto/ tema e/ou o prestígio do autor interessam.

A meu juízo, tais fatores, entre tantos outros, agravam o nosso poder de decisão, haja vista um forte (e inconciliável) desacordo político (nem tão razoável/fundamentado assim) acerca de qual é o papel da ciência e da Academia no país como o nosso. Sem saber o que é qualidade acadêmico-científica, discordando (por vezes, apenas ideologicamente, no pior sentido desse termo) das prioridades sociais e políticas, bem como ultrapassando extravagantemente os limites das nossas funções (por vezes, meramente para favorecer nossos interesses e prejudicar os dos outros, numa relação de poder espúria), seguimos contabilizando números.

Em resumo, diante dos problemas apontados, criamos uma ficção com pretensão de objetividade e neutralidade, qual seja: extrairemos a qualidade da quantidade, identificaremos o avanço acadêmico-científico por meio da quantificação. Mas, para mim, as propriedades de um critério não são adequadas para extrair/expressar as do outro; a natureza qualitativa não parece poder ser rebatida/espelhada pela quantitativa, e vice-versa. Ainda não está claro, nem para os defensores dos indicadores quantitativos, como vimos, por que e em que medida aquilo seria possível. Por que a quantidade de artigos publicados expressaria a qualidade de um pesquisador ou da ciência brasileira; ou por que a quantidade de citações expressaria a qualidade de um artigo e/ou de um periódico? E daí por diante.

A fim de estabelecer uma ponte para a próxima seção deste artigo, um dos possíveis e (principais) efeitos colaterais deturpadores da 'febre da publicação', de um contexto em que ou se publica, ou se perece, são as chamadas más condutas científicas (práticas antiéticas em publicação). Entre as mais citadas, estão: plágio ${ }^{8}$, fabricação (ou invenção de dados) ${ }^{9}$, falsificação ${ }^{10}$ (denominada internacional de FFP definition, o que chamei de tríade fóbica, destacando sua insuficiência para abarcar o problema das más condutas; VILAÇA, 2013; VILAÇA, 2015a) e, menos frequente, o autoplágio ${ }^{11}$. Em nome da chamada integridade em pesquisa (expressão que ultrapassa a ética em publicação, mas a contempla; dado o escopo deste texto, darei especial atenção ao que diz respeito a esse ponto), têm sido alvo de combate e de punição aos identificados. Abaixo, além de uma breve explanação ${ }^{12}$ sobre

8 Segundo o CNPq (2011), "consiste na apresentação, como se fosse de sua autoria, de resultados ou conclusões anteriormente obtidos por outro autor, bem como de textos integrais ou de parte substancial de textos alheios sem os cuidados detalhados nas Diretrizes. Comete igualmente plágio quem se utiliza de ideias ou dados obtidos em análises de projetos ou manuscritos não publicados aos quais teve acesso como consultor, revisor, editor, ou assemelhado".

9 Segundo o CNPq (2011), "consiste na apresentação de dados ou resultados inverídicos".

10 Conforme CNPq (2011), “consiste na manipulação fraudulenta de resultados obtidos de forma a alterar-Ihes o significado, sua interpretação ou mesmo sua confiabilidade. Cabe também nessa definição a apresentação de resultados reais como se tivessem sido obtidos em condições diversas daquelas efetivamente utilizadas".

11 De acordo com o CNPq (2011), "consiste na apresentação total ou parcial de textos já publicados pelo mesmo autor, sem as devidas referências aos trabalhos anteriores".

12 Para uma abordagem mais detalhada, ver Vilaça (2017). 
julho/2018

algumas das principais iniciativas, teço breves comentários críticos sobre como ser íntegro/ ético em um contexto como o que descrevi e problematizei, breve e pontualmente ${ }^{13}$, acima.

\section{OS DESAFIOS DA INTEGRIDADE EM TEMPOS DE PRESSÃO POR PUBLICAÇÃO}

Os casos (descobertos) de más condutas têm chocado a comunidade internacional (KNOBEL, 2003; XIN, 2006). Com isso, um movimento pela integridade em pesquisa tem se disseminado pela comunidade acadêmico-científica ao redor do mundo. Offices, comitês, comissões, declarações, etc. vêm dedicando-se a, via de regra, criar o que tem sido denominado de Código de Boas Práticas Científicas, expondo uma preocupação com a promoção de uma postura/atitude ética entre os pesquisadores. Eventos vêm sendo organizados ao redor do mundo, a fim de tematizar e conscientizar. Vejamos, com grande brevidade, como o tema da integridade em pesquisa tem sido abordado fora e dentro do Brasil (seleciono algumas das que abordei em VILAÇA, 2017).

Segundo o Office of Research Integrity (ORI, 2006), o conceito de integridade científica pode ser definido como a adesão ativa aos princípios éticos e normas profissionais essenciais para a prática responsável em pesquisa. Por adesão ativa, entende-se a adoção dos princípios e prática considerados éticos como um credo pessoal, e não meramente por uma imposição externa. Por princípios éticos, entende-se a honestidade, tida como a regra de ouro, a confiabilidade e o respeito pelos relatórios científicos (artigos ou quaisquer outras formas).

De acordo com a European Science Foundation (ALLEA, 2017), os princípios fundamentais da integridade em pesquisa estão na base das boas práticas, servindo como guia para a conduta dos pesquisadores, estabelecendo seu compromisso prático, ético e intelectual diante dos desafios inerentes à pesquisa. São eles (ALLEA, 2017, p. 4):

\footnotetext{
- Confiabilidade na garantia da qualidade da pesquisa, refletida no desenho, metodologia, análise e uso dos recursos;

- Honestidade no desenvolvimento, realização, revisão e relatório, comunicando a pesquisa de forma transparente, justa, completa e imparcial;

- Respeito pelos pares, pelos participantes da pesquisa, pela sociedade, pelo ecossistemas, patrimônio cultural e pelo meio ambiente;

- Responsabilidade pela pesquisa, desde a sua concepção (ideia) até a publicação, pela sua gestão e organização, pelo treinamento, supervisão e orientação, bem como pelos seus impactos amplamente falando.
}

O Singapore Statement on Research Integrity (WCRI, 2010, s/p.), um dos documentos mais importantes no cenário internacional, estabelece os seguintes princípios da integridade em pesquisa:

13 Para uma abordagem mais detalhada, ver Vilaça (2013). 
- Honestidade em todos os aspectos da pesquisa;

- Responsabilidade na condução de pesquisas;

- Cortesia profissional e lealdade (fairness) no trabalho com outros pesquisadores;

- Bom gerenciamento da pesquisa para atender aos interesses coletivos (on behalf of others).

Sobre as responsabilidades, dispõe que (WCRI, 2010, s/p.):

1. Integridade: os pesquisadores devem assumir a responsabilidade pela confiabilidade de sua pesquisa.

2. A adesão aos regulamentos: os investigadores devem estar conscientes e aderir aos regulamentos e políticas relacionadas à pesquisa.

3. Métodos de pesquisa: os pesquisadores devem empregar métodos de pesquisa apropriados, basear suas conclusões na análise crítica das evidências e reportar os resultados e interpretações completa e objetivamente.

4. Os registros de pesquisa: os pesquisadores devem manter registros claros e precisos de todas as pesquisas, a fim de permitir a verificação e replicação do seu trabalho.

5. Resultados de pesquisa: os pesquisadores devem compartilhar dados e resultados aberta e prontamente, a fim de estabelecer prioridade e reivindicar propriedade.

6. Autoria: os pesquisadores devem assumir a responsabilidade por suas contribuições em todas as publicações, pedidos de financiamento, relatórios e outras representações de suas pesquisas. As listas de autores devem incluir todos aqueles, e somente aqueles, que atendem aos critérios de autoria pertinentes.

7. Reconhecimento publicação: os pesquisadores devem reconhecer em publicações os nomes e funções das pessoas que fizeram contribuições significativas para a pesquisa, incluindo escritores, financiadores, patrocinadores e outros, mas que não satisfazem os critérios de autoria.

8. Revisão por pares: os pesquisadores devem elaborar avaliações justas, rápidas e rigorosas, respeitando a confidencialidade ao avaliar o trabalho de outros pesquisadores.

9. Conflito de interesse: os pesquisadores devem revelar conflitos de interesse financeiros ou não que possam comprometer a confiabilidade do seu trabalho em propostas de pesquisa, publicações e comunicações públicas, bem como em todas as atividades de revisão.

10. Comunicação pública: os pesquisadores devem limitar seus comentários profissionais nas suas áreas de expertise quando envolvidos em discussões públicas sobre a aplicação e importância dos resultados da pesquisa, claramente distinguindo comentários profissionais de opiniões com base em pontos de vista pessoais.

11. Relatório de práticas de investigação irresponsáveis: os pesquisadores devem comunicar às autoridades competentes qualquer suspeita de má conduta de pesquisa, incluindo fabricação, falsificação ou plágio, entre outras práticas de pesquisa irresponsáveis que minam a credibilidade da investigação, tais como negligência (carelessness), inclusão indevida de autores, omissão de dados conflitantes ou a utilização de métodos analíticos enganadores. 
12. Respondendo às práticas irresponsáveis de investigação: as instituições de investigação, bem como periódicos, organizações profissionais e agências de pesquisa devem ter procedimentos para responder a alegações de má conduta e de outras práticas de pesquisa irresponsáveis, protegendo aqueles que relatam esse tipo de comportamento em boa-fé. Quando uma conduta imprópria ou outra prática de pesquisa irresponsável for confirmada, as ações apropriadas devem ser tomadas prontamente, incluindo a correção do registro da pesquisa.

13. Ambientes de pesquisa: instituições de pesquisa devem criar e manter ambientes que estimulem a integridade por meio da educação, políticas claras e padrões razoáveis de progresso, enquanto promove ambientes de trabalho que suportam a integridade em pesquisa.

14. Considerações sociais: pesquisadores e instituições de pesquisa devem reconhecer que têm a obrigação ética de pesar os benefícios sociais contra os riscos inerentes ao seu trabalho.

No Brasil, duas agências de fomento destacam-se no tocante à tentativa de gerar uma normatização da conduta do pesquisador, a saber: Fundação de Amparo à Pesquisa do Estado de São Paulo (FAPESP) e Conselho Nacional de Desenvolvimento Científico e Tecnológico (CNPq).

No Código de Boas Práticas Científicas da FAPESP, publicado originalmente em 2011, afirma-se que a integridade ética da pesquisa - expressão adotada no documento é definida pelas normas de conduta aplicadas ao cientista, as quais derivam da finalidade específica da sua profissão. Mais à frente, lê-se que

As diretrizes estabelecidas neste código concernem a uma parte da esfera da ética profissional do cientista. Elas concernem apenas à integridade ética da pesquisa científica enquanto tal, ou seja, aos valores e padrões éticos de conduta que derivam direta e especificamente do compromisso do cientista com a finalidade mesma de sua profissão: a construção coletiva da ciência como um patrimônio coletivo. Partindo-se do princípio de que as questões de integridade ética da pesquisa devem ser objeto de autorregulação e autocontrole por parte da comunidade científica, sua codificação pretende auxiliar os pesquisadores a responder, em situações particulares, às seguintes questões. Como devo conduzir minhas atividades de pesquisa para que delas resulte a melhor contribuição à ciência? Como devo me conduzir em relação a outros pesquisadores para que a comunidade científica funcione e se reproduza da melhor maneira? (FAPESP, 2014, p. 15-16).

A leitura de outro trecho revela quais são os valores que orientam (ou devem orientar) a conduta (ética) do pesquisador:

Estas diretrizes [para as atividades científicas] ${ }^{14}$ repousam sobre o princípio geral de que todo cientista é eticamente responsável pelo avanço da ciência. Na concepção,

14 No código, as diretrizes são subdivididas em 3.1 - Sobre a concepção, a proposição e a realização da pesquisa; 3.2 - Sobre a comunicação dos resultados da pesquisa e autoria; 3.3 - Sobre o registro, conservação e acessibilidade de dados e informações; 3.4 - Sobre o conflito potencial de interesses; 3.5 - Sobre a avaliação pelos pares; 3.6 - Sobre a tutoria. 
proposição e realização de pesquisas, na comunicação de seus resultados e nas relações de cooperação e tutoria com outros pesquisadores, o cientista deve conduzir-se com honestidade intelectual, objetividade e imparcialidade, veracidade, justiça e responsabilidade. A presunção de que esses valores prevalecem na atividade de pesquisa é inseparável da presunção da fidedignidade dos resultados dessa atividade, sendo, por isso, condição de possibilidade da construção, apropriação e usufruto coletivos da ciência (FAPESP, 2014, p. 21).

No que diz respeito especificamente à publicação de artigos (3.2. Sobre comunicação dos resultados da pesquisa e a autoria), a FAPESP (2014, p. 22-23) normatiza:

3.2.1. Ao comunicar os resultados de sua pesquisa, por meio de um trabalho científico, o pesquisador deve expô-los com precisão, assim como todos os dados, informações e procedimentos que julgue terem sido relevantes para sua obtenção e justificação científicas. Nas situações em que essa exposição seja inviabilizada por razões éticas ou legais, esse fato deve ser expressamente mencionado no trabalho.

3.2.2. Um trabalho científico que exponha resultados de pesquisa realizada em situação de conflito potencial de interesses (ver seção 2.4 abaixo) deve conter, de maneira clara e destacada, a declaração de existência desse conflito. De modo geral, o trabalho deve conter a indicação expressa de todas as fontes de apoio material, direto ou indireto, à realização e divulgação da pesquisa.

3.2.3. Em um trabalho científico, pressupõe-se que toda ideia ou formulação verbal, oral ou escrita, que seja nele utilizada e não seja evidentemente de domínio público na área de pesquisa em questão, seja uma contribuição original dos pesquisadores indicados como autores do trabalho. Se não for esse o caso, a ideia ou formulação deve ser expressamente creditada, no trabalho, a seus autores, independentemente de já ter sido por eles divulgada em trabalho científico.

3.2.4. Todo pesquisador que submeta a um veículo de publicação trabalho científico idêntico, ou substancialmente semelhante, a trabalho também submetido a outro veículo, ou já publicado em outro veículo, deve declarar expressamente o fato ao editor do veículo no momento da submissão.

3.2.5. Todo pesquisador que publicar trabalho científico idêntico, ou substancialmente semelhante, a trabalho já publicado deve mencionar expressa e destacadamente o fato no texto do trabalho.

3.2.6. Em um trabalho científico devem ser indicados como seus autores todos e apenas os pesquisadores que, tendo concordado expressamente com essa indicação, tenham dado contribuições intelectuais diretas e substanciais para a concepção ou realização da pesquisa cujos resultados são nele apresentados. Em particular, a cessão de recursos infraestruturais ou financeiros para a realização de uma pesquisa (laboratórios, equipamentos, insumos, materiais, recursos humanos, apoio institucional, etc.) não é condição suficiente para uma indicação de autoria de trabalho resultante dessa pesquisa.

3.2.7. Cada um dos autores de um trabalho científico é responsável pela qualidade científica desse trabalho como um todo, a menos que os limites de sua contribuição científica para a obtenção dos resultados expostos no trabalho sejam nele expressa e precisamente definidos.

O Relatório da Comissão de Integridade de Pesquisa do CNPq, também publicado em 2011, estabelece as diretrizes de uma conduta íntegra (CNPQ, 2011, s/p,): 
1: O autor deve sempre dar crédito a todas as fontes que fundamentam diretamente seu trabalho.

2: Toda citação in verbis de outro autor deve ser colocada entre aspas.

3: Quando se resume um texto alheio, o autor deve procurar reproduzir o significado exato das ideias ou fatos apresentados pelo autor original, que deve ser citado.

4: Quando em dúvida se um conceito ou fato é de conhecimento comum, não se deve deixar de fazer as citações adequadas.

5: Quando se submete um manuscrito para publicação contendo informações, conclusões ou dados que já foram disseminados de forma significativa (p.ex. apresentado em conferência, divulgado na internet), o autor deve indicar claramente aos editores e leitores a existência da divulgação prévia da informação.

6: se os resultados de um estudo único complexo podem ser apresentados como um todo coesivo, não é considerado ético que eles sejam fragmentados em manuscritos individuais.

7: Para evitar qualquer caracterização de autoplágio, o uso de textos e trabalhos anteriores do próprio autor deve ser assinalado, com as devidas referências e citações. 8: O autor deve assegurar-se da correção de cada citação e que cada citação na bibliografia corresponda a uma citação no texto do manuscrito. O autor deve dar crédito também aos autores que primeiro relataram a observação ou ideia que está sendo apresentada.

9: Quando estiver descrevendo o trabalho de outros, o autor não deve confiar em resumo secundário desse trabalho, o que pode levar a uma descrição falha do trabaIho citado. Sempre que possível consultar a literatura original.

10: Se um autor tiver necessidade de citar uma fonte secundária (p.ex. uma revisão) para descrever o conteúdo de uma fonte primária (p. ex. um artigo empírico de um periódico), ele deve certificar-se da sua correção e sempre indicar a fonte original da informação que está sendo relatada.

11: A inclusão intencional de referências de relevância questionável com a finalidade de manipular fatores de impacto ou aumentar a probabilidade de aceitação do manuscrito é prática eticamente inaceitável.

12: Quando for necessário utilizar informações de outra fonte, o autor deve escrever de tal modo que fique claro aos leitores quais ideias são suas e quais são oriundas das fontes consultadas.

13: O autor tem a responsabilidade ética de relatar evidências que contrariem seu ponto de vista, sempre que existirem. Ademais, as evidências usadas em apoio a suas posições devem ser metodologicamente sólidas. Quando for necessário recorrer a estudos que apresentem deficiências metodológicas, estatísticas ou outras, tais defeitos devem ser claramente apontados aos leitores.

14: O autor tem a obrigação ética de relatar todos os aspectos do estudo que possam ser importantes para a reprodutibilidade independente de sua pesquisa.

15: Qualquer alteração dos resultados iniciais obtidos, como a eliminação de discrepâncias ou o uso de métodos estatísticos alternativos, deve ser claramente descrita junto com uma justificativa racional para o emprego de tais procedimentos.

16: A inclusão de autores no manuscrito deve ser discutida antes de começar a colaboração e deve se fundamentar em orientações já estabelecidas, tais como as do International Committee of Medical Journal Editors.

17: Somente as pessoas que emprestaram contribuição significativa ao trabalho merecem autoria em um manuscrito. Por contribuição significativa entende-se realização de experimentos, participação na elaboração do planejamento experimental, análise de resultados ou elaboração do corpo do manuscrito. Empréstimo de equipamentos, obtenção de financiamento ou supervisão geral, por si só não justificam a inclusão de novos autores, que devem ser objeto de agradecimento. 


\begin{abstract}
18: A colaboração entre docentes e estudantes deve seguir os mesmos critérios. Os supervisores devem cuidar para que não se incluam na autoria estudantes com pequena ou nenhuma contribuição nem excluir aqueles que efetivamente participaram do trabalho. Autoria fantasma em Ciência é eticamente inaceitável.

19: Todos os autores de um trabalho são responsáveis pela veracidade e idoneidade do trabalho, cabendo ao primeiro autor e ao autor correspondente responsabilidade integral, e aos demais autores responsabilidade pelas suas contribuições individuais. 20: Os autores devem ser capazes de descrever, quando solicitados, a sua contribuição pessoal ao trabalho.

21: Todo trabalho de pesquisa deve ser conduzido dentro de padrões éticos na sua execução, seja com animais ou com seres humanos.
\end{abstract}

Tal conjunto de valores/diretrizes/normas pode ser, em geral, bem incontroverso. Afinal, quem pensaria (e defenderia publicamente) que devemos ser desonestos, irresponsáveis, desrespeitosos, fraudulentos, etc. ao desenvolver uma pesquisa/publicar um artigo? Plagiar, falsificar e fabricar pesquisas também são atitudes que despertam nosso senso moral ("há algo de errado nisso!"), mesmo diante de um contexto de pressão por publicação. Mas será que nosso tácito acordo racional em torno de algumas normas é suficiente para endossar a assertiva de Volpato (2012), para o qual "se Ihe disserem que a competição por publicação tem feito com que apareçam autorias fraudulentas, não acredite. Autoria fraudulenta decorre de desvio moral e ético"; "sob pressão, os desonestos optam pelo caminho mais fácil, que é a fraude" (VOLPATO, 2012, s/p)?

Tentarei ser breve, resumindo-me a fazer algumas provocações relativas a um ponto sobre o qual tenho me debruçado insistentemente: a importância da pressão por publicação sobre o comportamento ético dos pesquisadores. Não serei muito sistemático e prolixo a partir de agora. Conto com a compreensão do leitor.

Devemos ser íntegros, mas... e o contexto de pressão por publicação, a lógica concorrencial ('melhores' x 'piores', 'produtivos' x 'improdutivos', 'programas de pós-graduação de excelência' x 'programas nota 3', etc.) e o modelo quantitativo de avaliação? Eles não influenciam de modo algum a conduta dos pesquisadores? Não haveria casos em que o pesquisador (indivíduo) seja pressionado/constrangido/induzido a agir de modo questionável por causa da lógica em vigor (do contexto)?

Como já argumentei (VILAÇA, 2015b), a pressão por publicação (a percepção sobre ela e seus efeitos) depende de elementos objetivos e subjetivos, variando tanto entre os indivíduos quanto em relação às áreas e subáreas. Em um estudo com dados de 1994-2013, mostrei, como pesquisadores Bolsistas de Produtividade em Pesquisa do CNPq (Nível 1A) de áreas distintas podem ter um perfil muitíssimo distinto de produtividade (publicação de artigos). Outra ressalva importante, que já fiz outras vezes, é que a pressão por publicação não explica todas as posturas, menos ainda as absolve.

Dito de modo genérico, presumo que seja possível manter-se íntegro e, ao mesmo tempo, preservar-se no ambiente acadêmico-científico. Ou seja, não estou partindo do princípio (falso - incorrendo numa petição de princípio) de que todos que se mantêm produtivos (com uma quantidade de publicação de acordo com a meta estabelecida pelas 
áreas na avaliação da CAPES ${ }^{15}$ ) estão cometendo, necessariamente, alguma má conduta. Em Vilaça (2015b), busquei mostrar/argumentar que um alto número de artigos publicados não significa, por si só, que houve a prática de más condutas/práticas antiéticas. Ou seja, não estou estabelecendo uma relação de tipo causa-efeito, aderindo à falácia post hoc ergo propter hoc, dizendo que a pressão por publicação causa, por si só, más condutas. Minha ideia, em resumo, é que ela é um fator que não pode, de modo algum, ser desconsiderado, pois o pesquisador, como qualquer outro ser humano/moral/social, age em um contexto, havendo elementos que influenciam sua conduta, restringem sua liberdade, orientam (em parte) sua tomada de decisão, interferem na sua autonomia. Em suma, o sujeito-pesquisador não é um ser abstrato que toma decisões com base em princípios a priori, desconsiderando seus interesses, emoções, seu sentido de autopreservação, sua necessidade de bem-estar/ segurança e as possíveis consequências (boas/ruins), elementos fundamentais do comportamento moral que guardam clara conexão com o contexto vivido.

Não obstante, a pressão por publicação também não pode ser considerada uma ficção dos improdutivos, como alguns querem fazer crer (já demonstrei a improcedência dos seus argumentos, de modo que não os retomarei aqui). Além dos trechos já citados na segunda seção deste artigo, cito a afirmação de Dowbor (2011, p. 34): sou "obrigado a publicar, pois sem isso o programa da PUC-SP, onde sou professor, não terá pontos necessários ao seu credenciamento". O termo usado pelo autor é claro: obrigação! Embora seja um pesquisador experiente, não estamos diante de um sujeito abstratamente livre e completamente autônomo (o que sequer existe), mas de alguém que se sente induzido/ obrigado/forçado a fazer algo.

E se o pesquisador não estiver em um momento muito criativo/produtivo? E se problemas de ordem pessoal (doença, nascimento de um filho, separação, por exemplo), profissional (perseguições, por exemplo) ou sociopolítica (corte de verbas, por exemplo) o impedirem de cumprir as metas? Num jogo de palavras, é possível a integridade (correção ética) sem que integridade (totalidade) do que somos seja considerada?

Vejamos o que afirmei em outro momento (VILAÇA, 2015b, p. 300)

Dito isso, observo o fato de que a política cientométrica vigente tem comprimido a liberdade dos docentes/pesquisadores, impondo-lhe fortes restrições e a condição do que denomino de homo accommodatus (homem adaptado ou que se adapta) (VILAÇA, 2013). Em outras palavras, os sujeitos-docentes-pesquisadores têm, via de regra, tido de se adaptar às regras do jogo. Com isso, mais do que uma meritocracia, penso que vivemos sob uma lógica da adaptocracia, o que apontaria para a pertinência do aforismo publicar e perecer. Talvez o grande mérito dos entes (PPG, pesquisador e periódico) 'bem-sucedidos' seja adaptarem-se pronta e eficazmente às regras do jogo, o que, por vezes, produz o seu perecimento ético, científico e político [psicológico e existencial, gostaria de acrescer].

15 Cada área estabelece uma forma de mensuração para classificar um programa de pós-graduação (como muito bom, bom, regular, fraco ou insuficiente) no quesito Produção Intelectual (quarto), o que interfere no conceito final $(7,6,5,4$ ou 3) conferido ao programa. Tais formas vêm se alterando ao longo do tempo, em parte, por causa das críticas feitas ao modelo quantitativo implementado. Para detalhes, ver Documentos de Área da Avaliação Quadrienal 2017 (disponível em: < http://avaliacaoquadrienal.capes.gov.br/documentos-de-area >). 
Segundo Fanelli (2010, p. 1), um autor-referência no debate em tela, "a objetividade e integridade da ciência contemporânea enfrentam muitas ameaças", sendo que "uma causa de particular preocupação é a crescente competição por financiamento de pesquisas e posições acadêmicas, que, combinada com o uso crescente de parâmetros bibliométricos para avaliar carreiras (por exemplo, número de publicações e fator de impacto dos periódicos em que são publicados), pressiona os cientistas a produzirem continuamente resultados 'publicáveis'". No resumo, Fanelli (2010, p. 1) afirma que:

A competição crescente e a cultura de "publicar ou perecer" na academia podem entrar em conflito com a objetividade e integridade da pesquisa, porque força os cientistas a produzir resultados "publicáveis" a todo custo. Os trabalhos têm menor probabilidade de serem publicados e de serem citados se reportarem resultados "negativos" (resultados que não suportam a hipótese testada). Portanto, se as pressões de publicação aumentam o viés científico, a frequência de resultados "positivos" na literatura deve ser maior nos ambientes acadêmicos mais competitivos e "produtivos".

Retomando argumento já desenvolvido (VILAÇA, 2015a; VILAÇA; PALMA, 2016), as chamadas más condutas ou práticas antiéticas em publicação podem ser antes uma tentativa (questionável, é claro) de 'se salvar' do que um ato desonesto deliberado e 'sem-vergonha', 'coisas de desonestos', como afirma Volpato (2012).

Como Fanelli (2010) aponta, os periódicos têm uma predileção por resultados positivos, por hipóteses confirmadas, por pesquisadores que 'não fracassam' na busca pelo saber (como se resultados negativos fossem sinal de fracasso). Sendo assim, como coadunar os mandamentos éticos "não fabricarás" e "não falsificarás" com a demanda do mercado acadêmico? Num cenário como esse, como cumprir integralmente as responsabilidades 3, 4 e 11 da Singapore Statement on Research Integrity? Ou ao indivíduo cabe resistir À tentação e trilhar a via crucis da improdutividade ou da 'falta de impacto' (publicação em periódicos com baixíssimo valor no mercado acadêmico-científico), esperando que, um dia, sem que o contexto mude, sua firmeza de caráter (sua 'santidade' acadêmica) seja, enfim, recompensada?

Passemos a outro exemplo. A definição de autoplágio é clara. Não devemos republicar trechos ou textos, sem avisar à comunidade. Mas qual a chance de publicar um novo artigo, caso sejamos honestos? Em um momento em que ser 'inovador' é uma espécie de 'virtude acadêmica', a reafirmação de teses, ideias, perspectivas pode ser vista como um vício imperdoável, reduzindo as chances de uma (nova) publicação. A autocitação também parece ser vista, nalguns contextos, como uma espécie de pecado. Em suma, à semelhança do que foi identificado por Fanelli (2010), o contexto pode estar enviesando as condutas dos pesquisadores, que, no afã de cumprir/bater suas metas quantitativas, omitem que tal ideia ou argumento já foi publicada anteriormente por ele mesmo.

Quanto à definição de autoria, também estamos diante de certos impasses: (1) alguns termos utilizados na definição de autoria adotada 'oficialmente' ${ }^{16}$ são de difícil

16 2. Quem é um autor? O ICMJE recomenda que a autoria se baseie nos seguintes 4 critérios: Contribuições substanciais para a concepção ou desenho do trabalho; ou a aquisição, análise ou interpretação de dados para o 
determinação (substancial, criticamente, importante, devidamente), abrindo espaço para diferentes ajuizamentos; (2) alguém pode não participar da análise dos dados ou da sua interpretação, mas, ainda assim, contribuir substancialmente para sua elaboração ou revisão 'crítica'?; (3) como alguém pode assegurar que possíveis questões de precisão ou integridade relacionadas ao trabalho serão devidamente investigadas e resolvidas? Em suma, quem pode ser autor de um artigo? Quem decide isso? Cada um ou ninguém? Todos preenchem todos os critérios? A pressão por publicação seria compatível com a complexidade das exigências supracitadas? O risco do cumprimento estrito de todos os quesitos não inviabilizaria a vida acadêmica?

Ainda no campo da autoria, como já destaquei em outros trabalhos (VILAÇA; PEDERNEIRA, 2013), há periódicos que, explicitamente, não aceitam a submissão de artigos de não-doutores sozinhos, o que dizer de graduandos. Assim, a coautoria forjada (convidar o orientador, por exemplo) não seria uma saída para a entrada no 'seleto' mundo acadêmico?

Insistindo um pouco mais no campo da (co)autoria, se considerarmos os custos financeiros da publicação em certos periódicos prestigiosos (como vimos acima, notas de rodapé 4 e 5), será que um único autor teria como arcar com a publicação de um artigo, o que pode custar mais de $\mathrm{R} \$ 2.000,00$ ? Talvez certos convites (e o rateio dos custos) não sejam uma alternativa necessária para publicar entre 'os grandes'?

O campo da autoria é um dos mais férteis, mas encerrarei os exemplos por aqui.

Em alguns dos códigos citados, os pesquisadores teriam o dever ético de denunciar más condutas. Aí, pergunto ironicamente: quem arcará com as custas processuais-advocatícias relativas ao processo que o denunciado (mesmo que seja culpado) moverá contra o denunciante? E o corporativismo? E a fragilidade das instituições responsáveis pela investigação das denúncias?

O peso está sobre o indivíduo. Afinal, o que as instituições têm feito para cumprir a responsabilidade 13 da Singapore Statement on Research Integrity? Ou seja, o que elas têm feito para criar um ambiente de promoção da integridade em pesquisa, que não informar aos pesquisadores o que eles não devem fazer (ao mesmo tempo em que, tacita ou explicitamente, continuam estimulando a que publiquem mais)?

Em suma, e por fim, as más condutas, por mais reprováveis que sejam, podem ser o que denominei em Vilaça e Palma (2016) de estratégia de conservatio vitae. Embora soe clichê e um pouco relativista, o fato é que, no mundo real, estratégias de autopreservação podem ser incontornáveis, se considerarmos certas necessidades básicas, como emprego/ trabalho/salário/comida/etc. Mas, num mundo ideal, eu endossaria (quase) toda lista de boas práticas que citei. Enquanto o mundo ideal não chega (e a selva publicacionista estiver aí), vivamos como meros humanos, com nossos erros e acertos, cedendo e resistindo às pressões. Quando concluo essa reflexão sobre o discurso da integridade, lembro de um

trabalho; E Elaborar o trabalho ou revisá-lo criticamente para conteúdo intelectual importante; E Aprovação final da versão a ser publicada; E Acordo para ser responsável por todos os aspectos do trabalho, assegurando que as questões relacionadas à precisão ou integridade de qualquer parte do trabalho sejam devidamente investigadas e resolvidas. Disponível em: <http://www.icmje.org/recommendations/browse/roles-and-responsibilities/ defining-the-role-of-authors-and-contributors.html > . Acesso em: 29 maio 2018. 
trecho de um pensador ${ }^{17}$ : "aquilo que o mundo (da integridade) me pede não é o que o mundo (do publicar ou perecer) me dá".

\section{REFERÊNCIAS}

ALLEA - ALL EUROPEAN ACADEMIES. The European Code of Conduct for Research Integrity, 2017. Revised Edition. Disponível em: < http://ec.europa.eu/research/ participants/data/ref/h2020/other/hi/h2020-ethics_code-of-conduct_en.pdf > ; p. 5. Acesso em: 29 maio 2018.

BOTOMÉ, S P. Avaliação entre "pares" na ciência e na academia: aspectos clandestinos de um julgamento nem sempre científico, acadêmico ou "de avaliação". Psicologia USP, v. 22, n. 2, p. 335-355, 2011.

CAMARGO JÚNIOR, K R. Public health and the knowledge industry. Revista de Saúde Pública, v. 43, n. 6, p. 1078-1083, 2010.

CNPq. Relatório da Comissão de Integridade de Pesquisa do CNPq, 2011. Disponível em: < http://www.cnpq.br/documents/10157/a8927840-2b8f-43b9-8962-5a2ccfa74dda > . Acesso em: 29 maio 2018.

DE MEIS, L. et al. The growing competition in brazilian science: rites of passage, stress and burnout. Brazilian Journal of Medical and Biological Research, v. 36, n. 9, p. 1.135-1.141, 2003.

DOWBOR, L. Criatividade ou lucro. O professor e a propriedade intelectual. Le Monde Diplomatique Brasil, ano 5, n. 51, p. 34-35, out. 2011. Disponível em: < https:// diplomatique.org.br/o-professor-e-a-propriedade-intelectual/> . Acesso em: 26 maio 2018.

FANELLI, D. Do Pressures to Publish Increase Scientists' Bias? An Empirical Support from US States Data. PLoS ONE, v. 5, issue 4, p. 1-7, 2010.

FAPESP. Código de boas práticas científicas, 2014. Disponível em: < http://www.fapesp. br/boaspraticas/FAPESP-Codigo_de_Boas_Praticas_Cientificas_2014.pdf $>$. Acesso em: 29 maio 2018.

KNOBEL, M. Fraudes sacodem a comunidade científica. Ciência \& Cultura, v. 55, n. 3, p. 17-18, 2003.

MARCOLIN, N; ZORZETTO, R. Mauricio da Rocha e Silva: O segredo da visibilidade. Pesquisa FAPESP, edição 191, janeiro de 2012. Disponível em: < http://revistapesquisa. fapesp.br/2012/01/16/mauricio-da-rocha-e-silva-o-segredo-da-visibilidade/ $>$. Acesso em: 28 maio 2018.

MINGERS, J; LEYDESDORFF, L. A Review of Theory and Practice in Scientometrics. European Journal of Operational Research, v. 246, issue 1, p. 1-19, Oct. 2015.

RODRIGUES, L. O. C. Publicar mais, ou melhor? O tamanduá olímpico. Revista Brasileira de Ciências do Esporte, v. 29, n. 1, p. 35-48, 2007. 
julho/2018

RUIZ, M A; GRECO, O T; BRAILE, D M. Fator de impacto: importância e influência no meio editorial, acadêmico e científico. Revista Brasileira de Hematologia e Hemoterapia, v. 24, n. 3, p. 273-278, jul./set. 2009.

SILVA, J A; BIANCHI, M L P. Cientometria: a métrica da ciência. Paidéia (Ribeirão Preto), v. 11, n. 21, p. 5-10, 2001.

ORI - The Office of Research Integrity. Teaching the Responsible Conduct of Research in Humans (RCRH), Chapter I: The ethical basis of RCRH. Disponível em: https://ori. hhs.gov/education/products/ucla/chapter1/page02.htm. Acesso em: 29 maio 2018.

VILAÇA, M M. Publicar ou perecer: uma análise crítico-normativa das características e dos efeitos dos modelos cientométrico e bibliométrico adotados no Brasil. 2013. Tese (Doutorado em Educação) - Universidade do Estado do Rio de Janeiro, Rio de Janeiro, 2013.

- Más condutas científicas. Uma abordagem crítico-comparativa para in-formar uma reflexão sobre o tema. Revista Brasileira de Educação, v. 20, n. 6, p. 245-269, jan./mar. 2015a.

. Dilemas e desafios da pós-graduação: pressão por publicação, produtivismo acadêmico e ética científica/em publicação. In: Simone Rechia et al. (Org.). Dilemas e desafios da pós-graduação em Educação Física. ljuí: Unijuí, 2015b, p. 283-305.

. Integridade em pesquisa. In. DIAS, M C (org.). Bioética: fundamentos teóricos e aplicações. Curitiba: Appris, 2017; p. 215-242

VILAÇA, M M; PALMA, A. Diálogo sobre cientometria, mal-estar na academia e a polêmica do produtivismo. Revista Brasileira de Educação, v. 18, n. 53, p. 467-484, abr./jun. 2013.

- Sobre coautoria, produtivismo e performatividade: um exercício críticohermenêutico. Educação e Filosofia, v. 30, n. 60, p. 917-949, jul./dez. 2016.

VILAÇA, M M; PEDERNEIRA, I. Assim é, se Ihe parece: "em-cena-ação" científica num país fictício em tempos de publicar ou perecer... mas bem que poderia ser no Brasil. Interface - Comunicação, Saúde, Educação, v. 17, n. 44, p. 235-241, jan./mar. 2013.

VOLPATO, G L. Autoria científica fraudulenta: causas, consequências e critérios. Entrevista publicada em 23 jan. 2012. Disponível em: < http://posgraduando.com/autoriacientifica-fraudulenta-causas-consequencias-e-criterios/>. Acesso em: 26 maio 2018.

XIN, H. Scandals shake chinese science. Science, v. 312, p. 1.464-1.466, 9 jun. 2006.

WORLD CONFERENCE ON RESEARCH INTEGRITY. Singapore Statement on Research Integrity, 2010. Disponível em: < http://www.singaporestatement.org/statement. html >. Acesso em: 29 maio 2018.

Autor convidado pela comissão editorial da Motrivivência para participar da Seção Temática dessa edição (21/fev/2018) 